\title{
Efeito da Concentração de Segmentos Rígidos nas Propriedades Físico-mecânicas, Químicas e na Morfologia de Elastômeros Microcelulares de Poliuretano
}

\author{
Marcos F. M. Pacheco \\ Autotravi Borrachas e Plásticos Ltda \\ Rudinei Fiorio, Ademir J. Zattera \\ Departamento de Engenharia Química, CCET, UCS \\ Mara Zeni, Janaina S. Crespo \\ Departamento de Física e Química, CCET, UCS
}

\begin{abstract}
Resumo: Neste trabalho, foram preparados três diferentes elastômeros microcelulares de poliuretano (EMPU) baseados em 4,4'- diisocianato de difenilmetano (MDI), com diferentes concentrações de fase rígida (Formulações 1, 2 e 3, com 32, 35 e $42 \%$ de fase rígida, respectivamente). As amostras foram preparadas através do método de duas etapas, pelo sistema de prépolímero. As amostras dos EMPU foram caracterizadas através de ensaios físico-mecânicos, químicos e morfológicos. Os resultados dos ensaios mecânicos mostraram que o aumento no percentual da fase rígida levou a um aumento na resistência à tração e na resistência ao rasgo. $\mathrm{O}$ alongamento na ruptura não apresentou variação significativa com a modificação do percentual da fase rígida. O ensaio de resistência química demonstrou que os EMPU formulados apresentaram baixos índices de inchamento para solventes industriais comumente utilizados. Entretanto, em acetona, um elevado índice de inchamento foi observado. As análises morfológicas indicaram que o aumento no percentual da fase rígida promoveu a formação de células menores distribuídas de forma mais homogênea no EMPU.
\end{abstract}

Palavras-chave: Elastômero microcelular de poliuretano, propriedades mecânicas, microscopia eletrônica de varredura.

\section{Effect of rigid Segment content on the Physical, Mechanical, Chemical and Morphological Properties of Microcellular Polyurethane Elastomers}

\begin{abstract}
In this study, three different microcellular polyurethane elastomers (MPUE) based on 4,4'-diphenylmethane diisocyanate (MDI) with different rigid segment contents were prepared (Formulations 1, 2 and 3 with 32, 35 and $42 \%$ of rigid segment content, respectively). The MPUE were obtained through a two-step method using the prepolymer system. The samples were analyzed to determine their physical, mechanical, morphological and chemical properties. The results showed that a greater rigid segment content gave higher tensile, compressive and tear strength values. The deformation at break did not show significant changes with a variation in the rigid segment content. The MPUE had a low swelling index in common industrial solvents. However, in acetone a high swelling index was observed. The SEM micrographs indicated a large number of closed cells, and that a higher rigid segment content gave a better cell homogeneity of the samples.
\end{abstract}

Keywords: Microcellular polyurethane elastomers, mechanical properties, scanning electron microscopy.

\section{Introdução}

Os poliuretanos (PUs) são considerados como copolímeros em bloco segmentados, formados pela reação de poliadição entre diisocianatos, polióis e extensores de cadeia ${ }^{[1-3]}$. Os mesmos são constituídos por segmentos rígidos e flexíveis ${ }^{[4,5]}$. A reação entre diisocianato e extensores de cadeia forma o segmento rígido, enquanto que o poliol é responsável pelo segmento flexível ${ }^{[2,4,5]}$.

Os elastômeros microcelulares de poliuretano (EMPU) são materiais que resistem a condições severas encontradas em diversas aplicações, como em automóveis e máquinas industriais ${ }^{[7,8]}$. Os mesmos apresentam uma densidade aparente uniforme, entre 0,40 e 0,80 g.cm ${ }^{-3}$, com a maior parte de suas células fechadas, as quais são tão pequenas que são difíceis de serem visualizadas a olho $\mathrm{nu}^{[7,9-11]}$. A maioria dos EMPU apresenta excelente resistência à abrasão, boa resistência a óleos, petróleo e a muitos solventes comuns não-polares. É possível se produzir PUs de propriedades variadas, o que possibilita a escolha do material mais adequado para cada aplicação, podendo-se assim optar por materiais mais

Autor para correspondência: Janaina S. Crespo, Grupo de Materiais Elastoméricos, Centro de Ciências Exatas e Tecnologia, Departamento de Física e Química, Universidade de Caxias do Sul, Rua Francisco Getúlio Vargas 1130, CEP: 95070-560, Caxias do Sul, RS, Brasil. E-mail: jscrespo@ucs.br. 
elásticos e macios, ou por materiais mais duros e de estrutura reticulada $^{[12]}$. Para aplicações como batentes, que podem entrar em contato com óleos e graxas, e que devem ser resistentes ao impacto, estuda-se como material para concepção do mesmo, o EMPU à base de MDI e poliol poliéster ${ }^{[13,14]}$.

Os EMPU têm sido estudados por alguns autores. Dai e colaboradores ${ }^{[15]}$ estudaram a morfologia e as propriedades de amortecimento de EMPU expandidos com $\mathrm{CO}_{2}$, e observaram que o tamanho e a distribuição das microcélulas podem ser convenientemente controlados através de modificações nas condições do processo. Esses autores também verificaram que os EMPU expandidos pelo método, por eles utilizado, apresentaram um aumento significativo nas propriedades de amortecimento. Korodi e colaboradore ${ }^{[13,14]}$ estudaram os efeitos da composição química e dos extensores de cadeia nas propriedades mecânicas dos EMPU, e observaram que a densidade apresentou grande influência na resistência à tração, enquanto que o alongamento na ruptura mostrou-se dependente, principalmente, da dispersão dos segmentos rígidos na matriz flexível. Os autores também observaram que o aumento na quantidade de extensores de cadeia levou a uma redução no alongamento na ruptura.

Neste trabalho, realizaram-se experimentos para a síntese de EMPU que possuíssem propriedades para aplicação como batente absorvedor de impacto. Uma vez obtidos, os EMPU foram caracterizados através de ensaios físico-mecânicos, químicos e morfológicos.

\section{Experimental}

\section{Materiais}

Os materiais utilizados para a obtenção dos EMPU foram: polióis poliésteres (Diexter G210 e Diexter G173, Coim), 4,4' - diisocianato de difenilmetano (MDI, Basf), extensor de cadeia (1,4-butanodiol, Basf), água destilada, catalisador (Dabco 33LV, Air Products), surfactante (Dabco DC193, Air Products), e desmoldante (Pura G21052W, Chem Trend).

\section{Preparação dos elastômeros microcelulares de poliuretano}

O cálculo estequiométrico para a preparação dos EMPU foi realizado utilizando-se as Equações 1, 2, 3 e $4^{[16,17]}$.

$$
\begin{aligned}
& E s=\frac{\overline{M s}}{f} \\
& E p=\frac{M_{K O H}}{O H} \\
& n=\frac{m}{E_{C}} \\
& I_{N C O}=\frac{n s}{n t}
\end{aligned}
$$

onde Es é o equivalente do MDI (g.mol $\left.{ }^{-1}\right) ; M s$ é a massa molar do MDI (g.mol ${ }^{-1}$ ); f é a funcionalidade do MDI; $E p$ é o equivalente do poliol poliéster $\left(\mathrm{g} \cdot \mathrm{mol}^{-1}\right) ; M_{K O H}$ é a massa molar do $\mathrm{KOH}\left(\mathrm{g} \cdot \mathrm{mol}^{-1}\right) ; \mathrm{OH}$ é o teor de hidroxila livre do poliol poliéster determinado por titulação com $\mathrm{KOH} ; n$ é o número de mol de cada componente (mol); $m$ é a massa de cada componente $(\mathrm{g}) ; E_{C}$ é o equivalente de cada componente $\left(\mathrm{g} \cdot \mathrm{mol}^{-1}\right) ; I_{N C O}$ é o índice de NCO; ns é o número de mol do MDI (mol); e $n t$ é o número de mol total de compostos com hidrogênio ativo (mol).

No cálculo estequiométrico das Formulações 1, 2 e 3, os percentuais de isocianato livre (NCO) utilizados foram de $15,7,16,7$ e $18,9 \%$, e os percentuais de segmento rígido (1,4 butanodiol + MDI) foram de 32, 35 e $42 \%$, respectivamente. O índice de NCO foi mantido em 105 para todas as formulações.

Os polióis poliésteres foram desgaseificados e desumidificados, sob vácuo, em reatores de aço inox, com agitação de $100 \mathrm{rpm}$ e temperatura de $80^{\circ} \mathrm{C}$, durante 2 horas. Após essa etapa, determinou-se o teor de água, através da titulação iodométrica, segundo Karl Fischer (ASTM D 4672 - 87) ${ }^{[18 a]}$.

Para a realização das misturas, o MDI e o poliol Diexter $\mathrm{G} 210$ foram mantidos a $45{ }^{\circ} \mathrm{C}$ por um período mínimo de 2 horas. Inicialmente, foram misturados o MDI e o poliol Diexter G210 em um misturador industrial, a 600 rpm durante 5 minutos, formando o componente A. Os percentuais de NCO livre do MDI e do componente A foram determinados por titulação com N-dibutilamina ${ }^{[18 b]}$. Em outro recipiente, foram misturados o poliol Diexter G173, o extensor de cadeia, a água destilada, o catalisador e o surfactante, a 6000 rpm durante 1 minuto, formando o componente B. As misturas entre os componentes A e B foram preparadas a $6000 \mathrm{rpm}$ durante 30 segundos. Após a etapa de mistura, as amostras foram vertidas em dois tipos de moldes fechados (molde 1: $120 \times 80 \times 2 \mathrm{~mm}$; molde 2: diâmetro $=28,6 \mathrm{~mm}$, espessura $=13 \mathrm{~mm}$ ) para obtenção dos corpos de prova. As amostras foram pós-curadas a $80{ }^{\circ} \mathrm{C}$ por um período de 24 horas ${ }^{[3,7]}$.

\section{Ensaios mecânicos}

Para a realização dos ensaios mecânicos, os corpos de prova foram acondicionados a $23 \pm 2{ }^{\circ} \mathrm{C}$ e umidade relativa de $50 \pm 5 \%$ durante 48 horas.

Os testes para determinação da densidade aparente e dureza (Shore A, durômetro Teclock) foram realizados, em triplicata, segundo normas ASTM D 3574A-95 ${ }^{[18 c]}$ e ASTM D 2240-95 ${ }^{[18 d]}$, respectivamente.

Os ensaios de resistência à tração, resistência ao rasgo e resistência à compressão das amostras dos EMPU foram realizados em um equipamento de ensaio universal EMIC modelo DL3000, de acordo com as normas ASTM D 412-98 ${ }^{[18 e]}$, ASTM D 624-98 ${ }^{[18 f]}$ e ASTM D 575-96 ${ }^{[18 g]}$, respectivamente. Para os ensaios de resistência à tração e resistência ao rasgo, foram utilizados cinco corpos de prova do tipo IV e tipo C, respectivamente, como especificado nas normas. A célula de carga utilizada foi de $2 \mathrm{kN}$ e a velocidade de separação das garras de $500 \mathrm{~mm} \cdot \mathrm{min}^{-1}$. A garra utilizada foi para ensaio de elastômeros. $\mathrm{O}$ ensaio de resistência à compressão foi realizado com cinco corpos de prova (diâmetro $=28,6 \mathrm{~mm}$, espessura $=13 \mathrm{~mm}$ ) sendo que os mesmos foram submetidos a três ciclos com uma taxa de compressão de $12 \mathrm{~mm} \cdot \mathrm{min}^{-1}$. 
Para o ensaio de deformação por compressão dinâmica, dois corpos de prova (diâmetro $=28,6 \mathrm{~mm}$, espessura $=$ $13 \mathrm{~mm}$ ) foram submetidos a 100.000 solicitações, sob uma pressão de $40 \pm 0,01 \mathrm{MPa}$. Nesse ensaio foi utilizada uma máquina de solicitações contínuas tipo DBPM, programada e controlada por computador, a uma freqüência de $1,0 \pm 0,1 \mathrm{~Hz}$. A medição dos corpos-de-prova foi efetuada imediatamente após os 100.000 ciclos de carga e após 24 horas de recuperação, com uma incerteza de medição de $\pm 0,5 \%$, de acordo com a norma S-014/ME:2004[19].

O ensaio de resiliência ao impacto por queda de bola foi realizado de acordo com norma ASTM D 3574 H-95 ${ }^{[18 h]}$. Foram utilizados três corpos de prova (diâmetro $=28,6 \mathrm{~mm}$, espessura $=13 \mathrm{~mm}$ ).

O ensaio de resistência à abrasão foi realizado em um equipamento Veb Thüringer Industriewerk Rauenstein, modelo AGPi, de acordo com norma DIN 53516-87 $7^{[20]}$. Foram utilizados três corpos de prova (diâmetro $=16 \mathrm{~mm}$, espessura $=13 \mathrm{~mm}$ ).

Os ensaios de deformação permanente à compressão foram realizados segundo a norma ASTM D 395 B- $98^{[18 i]}$, a $23 \pm 2{ }^{\circ} \mathrm{C}$. Foram utilizados três corpos de prova (diâmetro $=$ $28,6 \mathrm{~mm}$, espessura $=13 \mathrm{~mm}$ ) sendo que os mesmos foram mantidos 22 horas sob uma deformação de aproximadamente $25 \%$. A medida da espessura foi realizada após 30 minutos da retirada da amostra do equipamento.

\section{Microscopia eletrônica de varredura (MEV)}

A morfologia das amostras foi obtida em um microscópio eletrônico de varredura modelo PHILIPS XL30. As amostras foram fraturadas em nitrogênio líquido e metalizadas em um metalizador modelo P-S2 DIODE SPUTTERING SYSTEM. Foram obtidos valores de número de células e diâmetro mé- dio das células utilizando o software Image Tool, versão 5.1, Alpha 4.

\section{Resistência química}

Amostras dos EMPU foram imersas em $100 \mathrm{~mL}$ de água, gasolina, álcool combustível, óleo diesel, querosene, óleo automotivo, etanol, metanol, acetona, tolueno, xileno e soluções de $0,1 \mathrm{M}$ de $\mathrm{NaOH}$ e $0,1 \mathrm{M}$ de $\mathrm{HCl}$, para determinação do índice de inchamento, de acordo com norma ASTM D 3616$95^{[18 j]}$. Foram utilizados três corpos de prova $(1 \times 5 \times 2 \mathrm{~mm})$, sendo que os mesmos foram mantidos em imersão durante 18 horas, no escuro a $23 \pm 2{ }^{\circ} \mathrm{C}$. O índice de inchamento foi obtido pela razão entre a massa da amostra inchada e a massa inicial da amostra.

\section{Resultados e Discussão}

\section{Ensaios físico-mecânicos}

Na Tabela 1 estão ilustrados os valores obtidos através dos ensaios físico-mecânicos dos corpos de prova dos EMPU desenvolvidos.

É possível observar que os valores de densidade aparente foram similares e independentes da quantidade de segmento rígido presente nas formulações. Os resultados indicam que, apesar da dificuldade de dosagem do material nos moldes, o método de expansão e de obtenção dos corpos de prova escolhido foi satisfatório. O controle da densidade aparente é importante, visto que vários autores sinalizam que esse ensaio é relevante para as propriedades do material final ${ }^{[3,7,13,14,21]}$.

Analisando-se os resultados de dureza, observou-se que as Formulações 1 e 3 foram as que apresentaram, respectivamente, o menor e o maior valor para esse ensaio. Esses resultados indicam a dependência dessa propriedade em re-

Tabela 1. Resultados dos ensaios físico-mecânicos dos EMPU.

\begin{tabular}{|c|c|c|c|}
\hline \multirow[b]{2}{*}{ Ensaio } & \multicolumn{3}{|c|}{ Formulação } \\
\hline & 1 & 2 & 3 \\
\hline Densidade $\left(\mathrm{g} . \mathrm{cm}^{-3}\right)[0,60]^{*}$ & $0,66 \pm 0,037$ & $0,64 \pm 0,064$ & $0,64 \pm 0,072$ \\
\hline Dureza (Shore A) & $56 \pm 7$ & $59 \pm 6$ & $74 \pm 2$ \\
\hline Resistência à tração $(\mathrm{MPa})[5,5]^{*}$ & $2,02 \pm 0,23$ & $3,08 \pm 0,25$ & $5,03 \pm 0,60$ \\
\hline Alongamento na ruptura $(\%)[450]^{*}$ & $132,5 \pm 8,34$ & $126,5 \pm 10,3$ & $119,2 \pm 7,93$ \\
\hline Resistência ao rasgo $\left(\mathrm{kN} \cdot \mathrm{m}^{-1}\right)[21]^{*}$ & $7,51 \pm 1,01$ & $14,28 \pm 0,92$ & $22,25 \pm 2,08$ \\
\hline Desgaste por abrasão $\left(\mathrm{mm}^{3} / 40 \mathrm{~m}\right)$ & $171 \pm 12$ & $208 \pm 19$ & $253 \pm 25$ \\
\hline Resiliência $(\%)[56]^{*}$ & $48 \pm 2$ & $44 \pm 1$ & $42 \pm 1$ \\
\hline \multicolumn{4}{|l|}{ Deformação permanente à compressão } \\
\hline a $23{ }^{\circ} \mathrm{C}(\%)[4,7]^{*}$ & $4,37 \pm 0,05$ & $4,65 \pm 0,59$ & $7,03 \pm 0,75$ \\
\hline \multicolumn{4}{|l|}{ Deformação por compressão dinâmica } \\
\hline após 100.000 solicitações (\%) & $2,0 \pm 0,5$ & $2,4 \pm 0,5$ & $2,6 \pm 0,5$ \\
\hline após 24 horas de recuperação (\%) & $<0,5$ & $0,7 \pm 0,5$ & $1,2 \pm 0,5$ \\
\hline \multicolumn{4}{|l|}{ Resistência à compressão } \\
\hline 95\% de deformação & $27,3 \pm 1,08$ & $30,71 \pm 0,92$ & $38,3 \pm 0,33$ \\
\hline $25 \%$ de deformação & $0,81 \pm 0,04$ & $0,90 \pm 0,03$ & $1,35 \pm 0,07$ \\
\hline
\end{tabular}

*Dados do produto comercial dynathane ${ }^{[21]}$. 
lação à quantidade de segmento rígido presente no EMPU. Esse comportamento é explicado pela maior interação entre os segmentos rígidos promovida pelo aumento na quantidade de segmento rígido ${ }^{[22]}$, e também pela mais alta temperatura de transição vítrea $(\mathrm{Tg})$ dos segmentos rígidos, comparada à dos segmentos flexíveis ${ }^{[23]}$. $\mathrm{O}$ aumento na quantidade do segmento de maior Tg promoveu um aumento na dureza dos EMPU desenvolvidos.

Os resultados do ensaio de resistência à tração indicaram que os mais altos valores para essa propriedade foram obtidos, respectivamente, para as Formulações 1, 2 e 3. Observou-se que o aumento na quantidade do segmento rígido presente nos EMPU ocasionou um aumento no valor de resistência à tração. Comportamento similar foi observado por Bajsic e colaboradores ${ }^{[24]}$ e está relacionado ao efeito reforçante que o segmento rígido apresenta sobre as características do material $^{[1,2]}$.

Os resultados de alongamento na ruptura foram similares para as formulações utilizadas, quando são considerados os valores de desvio-padrão. Entretanto, observou-se uma tendência de redução no alongamento na ruptura com o aumento do percentual de segmento rígido presente nos EMPU. Resultado similar foi obtido por Lee e colaboradores ${ }^{[22]}$. Segundo esses autores, o aumento do percentual de segmentos rígidos torna o estiramento dos PUs mais difícil, devido ao fato desses segmentos estarem unidos por interações do tipo ligações de hidrogênio. Essas interações dificultam o estiramento das cadeias, o que reduz o alongamento na ruptura.

De forma similar àquela observada para a resistência à tração, as Formulações 1 e 3 apresentaram, respectivamente, o menor e o maior valor de resistência ao rasgo. Como o segmento rígido atua como uma carga reforçante no $\mathrm{PU}^{[1,2]}$, um aumento na percentual do mesmo implica em um aumento na interação entre os segmentos ${ }^{[22]}$. Isso implica em uma maior resistência ao rasgo dos EMPU.

Os resultados de resistência à abrasão indicaram que o aumento no percentual de segmento rígido promoveu uma redução na resistência à abrasão dos EMPU estudados. Com o aumento na quantidade de segmento rígido, houve uma maior remoção de massa das amostras, provavelmente devido à maior rigidez dos segmentos rígidos, quando comparada àquela apresentada pelos segmentos flexíveis. Como o segmento rígido apresenta baixa deformação elástica, o mesmo pode ser removido com maior facilidade do que o segmento flexível, quando as amostras são submetidas a um ensaio de abrasão.

Os resultados de resiliência demonstraram que a Formulação 1 apresentou o maior valor de resiliência, enquanto que a Formulação 3 apresentou a menor resiliência entre as três formulações utilizadas. Como esperado, o aumento no percentual de segmento rígido provocou uma redução na resiliência dos elastômeros, uma vez que as características elásticas dos PUs são devidas ao segmento flexível ${ }^{[1]}$.

Para os ensaios de deformação permanente à compressão a $23{ }^{\circ} \mathrm{C}$, os maiores valores de deformação permanente foram obtidos, respectivamente, para as Formulações 3, 2 e 1. Sabese que os segmentos rígidos são responsáveis pela reticulação dos PUs, através da reação entre isocianato e uretano, gerando grupos alofanato e/ou através da reação entre isocianato e uréia, gerando grupos biureto. Uma deformação dos segmentos rígidos pode promover o rompimento de ligações cruzadas, o que aumenta a mobilidade das cadeias poliméricas $^{[25]}$. Um EMPU com maior quantidade de segmento rígido $\mathrm{e}$, conseqüientemente, com uma maior densidade de reticulação, pode estar mais suscetível a sofrer rompimento de ligações cruzadas, devido à deformação. Dessa forma, o aumento no percentual de segmento rígido promoveu um aumento na deformação permanente à compressão a $23{ }^{\circ} \mathrm{C}$, associada à deformação plástica sofrida pelo segmento rígido durante a compressão, bem como ao rompimento de ligações cruzadas e redução das interações intersegmentos, o que dificultou a recuperação do material à deformação imposta.

Os resultados dos ensaios de deformação por compressão dinâmica após 100.000 solicitações mostraram que o aumento no percentual de segmento rígido conduziu a uma maior deformação das amostras. O mesmo comportamento foi observado para o ensaio de deformação por compressão dinâmica após 24 horas de recuperação. De maneira semelhante à deformação permanente à compressão a $23{ }^{\circ} \mathrm{C}$, o aumento da deformação por compressão dinâmica com o aumento do percentual de segmento rígido pode estar relacionado à deformação plástica que o segmento rígido sofre durante a compressão, bem como ao rompimento de ligações cruzadas e a redução das interações intersegmentos presentes na estrutura do material ${ }^{[25]}$.

Os resultados de resistência à compressão mostraram que o aumento no percentual de segmento rígido promoveu um aumento na resistência à compressão, tanto a $95 \%$ quanto a $25 \%$ de deformação. Com o aumento no percentual de segmento rígido ocorre um aumento na quantidade de ligações de hidrogênio, bem como uma redução na mobilidade das cadeias dos EMPU ${ }^{[25]}$. A maior interação entre as cadeias constituintes do material conduz a uma maior resistência à compressão para as amostras com maior percentual de segmento rígido.

\section{Microscopia eletrônica de varredura}

$\mathrm{Na}$ Figura 1 são mostradas as micrografias de MEV das Formulações 1, 2 e 3 desenvolvidas para a obtenção dos EMPU. Nas micrografias com um aumento de 50 vezes (Figura 1a, b e c) verificou-se a existência de numerosas microcélulas presentes nas três formulações. Também foi observado que as microcélulas formadas são relativamente esferoidais, não apresentando um determinado sentido de orientação, provavelmente devido ao método de expansão adotado (expansão em molde fechado). Os EMPU apresentaram diferentes tamanhos e distribuição relativamente homogênea das microcélulas formadas. Na Figura 1d encontra-se a micrografia da Formulação 2 com um aumento de 200 vezes. Nessa amostra verificou-se a predominância de microcélulas 


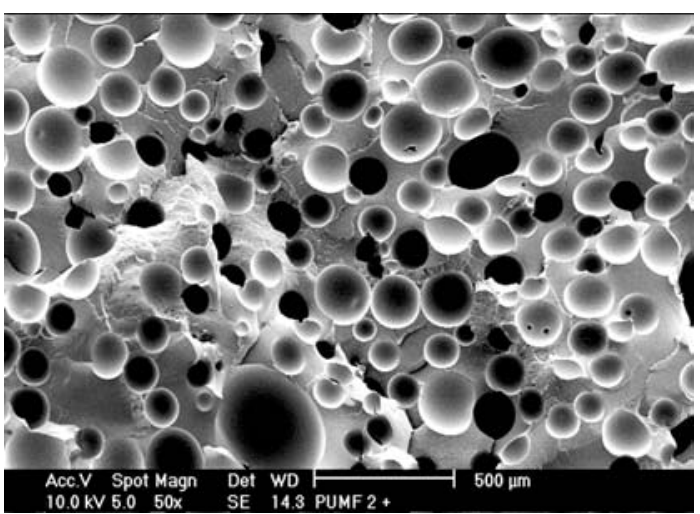

(a)

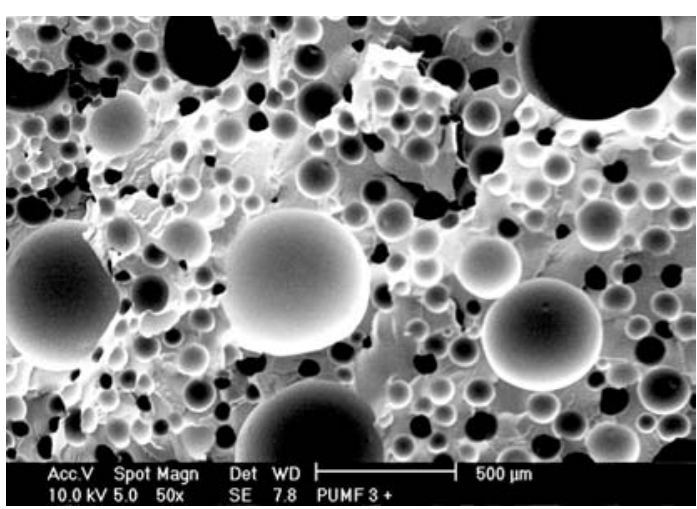

(b)

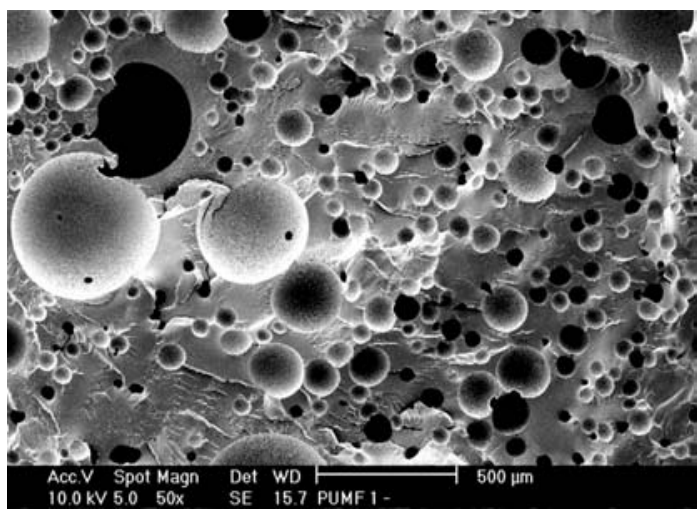

(c)

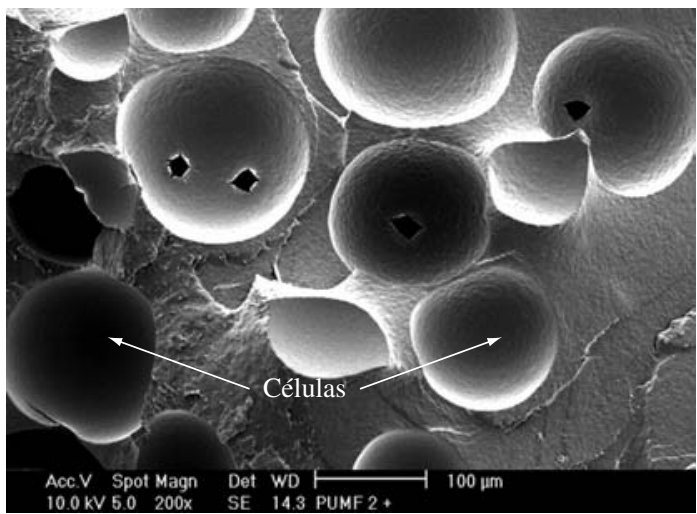

(d)

Figura 1. Micrografias de MEV dos EMPU. Aumento de 50x: a) formulação 1 ; b) formulação 2 ; e c) formulação 3 . aumento de $200 x$ : d) formulação 2 .
Tabela 2. Dados obtidos através do tratamento das micrografias de MEV dos EMPU, com o software Image Tool.

\begin{tabular}{lccc}
\hline & \multicolumn{3}{c}{ Formulação } \\
\cline { 2 - 4 } \multicolumn{1}{c}{ Dados } & $\mathbf{1}$ & $\mathbf{2}$ & $\mathbf{3}$ \\
\hline Número de células & 195 & 296 & 312 \\
Diâmetro médio das células $(\mu \mathrm{m})$ & 48,8 & 42,5 & 20,1 \\
\hline
\end{tabular}

fechadas. Esse comportamento foi observado nas três formulações estudadas nesse trabalho.

Dados sobre o número e o diâmetro médio das microcélulas estão descritos na Tabela 2.

Observou-se que para as três formulações desenvolvidas, o número de microcélulas é inversamente proporcional ao diâmetro médio das mesmas. Dessa forma, um acréscimo no percentual de segmento rígido provocou uma redução no diâmetro médio e um aumento no número de microcélulas. Isso indica que houve uma melhor mistura entre os componentes utilizados na formulação dos EMPU com o aumento no percentual de segmento rígido. A dispersão das microcélulas, dada pela mistura e pela atuação do surfactante ${ }^{[7,26]}$, foi mais eficiente na amostra da Formulação 3. Dai e colaboradores ${ }^{[15]}$ observaram que as espumas com menores diâmetros médios das microcélulas apresentaram melhores propriedades de resistência à tração e resistência ao rasgo. O mesmo comportamento foi observado neste trabalho.

\section{Resistência química}

Na Figura 2 estão apresentados os resultados de índice de inchamento encontrados para as diferentes formulações. O ensaio de resistência química demonstrou que os EMPU formulados apresentaram baixos índices de inchamento/boa resistência química em solventes industriais comumente utilizados, água e soluções ácidas e básicas. Entretanto, em acetona, um elevado índice de inchamento foi observado. Esse comportamento pode estar relacionado à semelhança entre os parâmetros de solubilidade dos

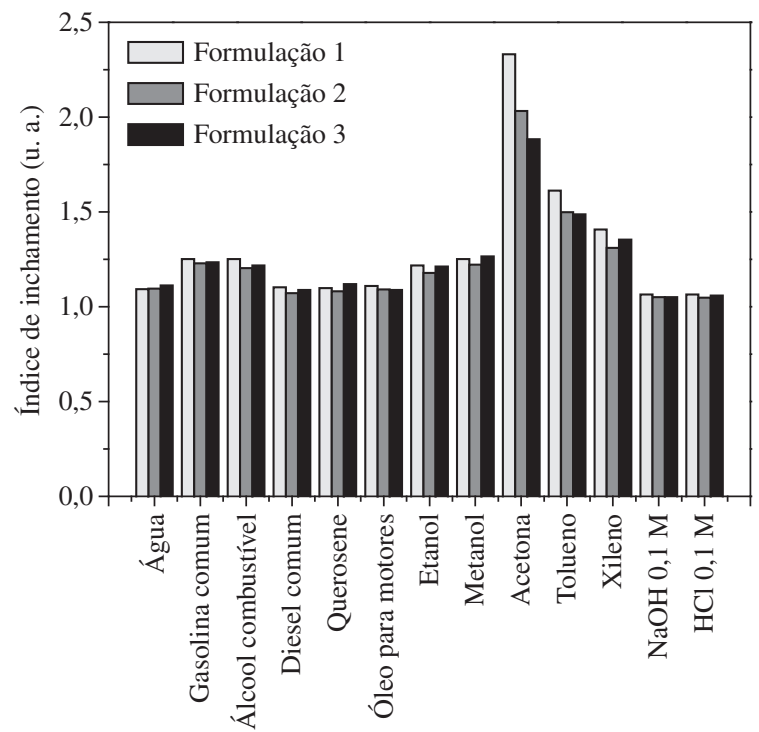

Figura 2. Índice de inchamento obtido em diversos solventes, para os EMPU. 
poliuretanos $\left(9,3 \text { a } 9,5\left(\mathrm{cal} \mathrm{cm}^{-3}\right) 1 / 2\right)^{[2,27]}$ e da acetona $\left(9,9\left(\mathrm{cal}^{\mathrm{cm}}{ }^{-3}\right) 1 / 2\right)^{[28,29]}$.

\section{Conclusões}

Foi possível a obtenção dos EMPU, utilizando-se o método em duas etapas pelo sistema de pré-polímero. O método de expansão utilizado foi satisfatório em relação ao controle da densidade aparente dos EMPU obtidos.

Os ensaios mecânicos mostraram que o aumento na quantidade de segmento rígido presente nos EMPU implicou em aumento na dureza, na resistência à tração, na resistência ao rasgo e na resistência à compressão, devido ao efeito reforçante que essa fase proporcionou ao material, bem como a um aumento no número de microcélulas devido a redução no diâmetro médio das mesmas.

As micrografias de MEV dos EMPU evidenciaram a predominância de microcélulas fechadas, distribuídas de maneira homogênea no material. A dispersão das microcélulas foi mais eficiente na amostra da Formulação 3.

O ensaio de resistência química demonstrou que os EMPU formulados apresentaram baixos índices de inchamento/boa resistência química em solventes industriais comumente utilizados, água e soluções ácidas e básicas.

Os resultados mostraram que os EMPU obtidos apresentaram propriedades de interesse industrial, com exceção do alongamento na ruptura, que pode ser melhorado com a troca da composição química do segmento flexível. A Formulação 3 foi a que apresentou o melhor conjunto de resultados.

\section{Agradecimentos}

Os autores agradecem à FAPERGS/PAPPE I (Processo n : 0406568) e à Empresa Autotravi Borrachas e Plásticos Ltda - Divisão Plásticos pelo auxílio financeiro; à Coim, Air Products e Chem Trend pelos materiais fornecidos.

\section{Referências Bibliográficas}

1. Frick, R. - Polymer Testing, 23, p.413 (2003).

2. Pompe, G.; Pohlers, A.; Pötschke, P. \& Pionteck, J. - Polymer, 31, p.5147 (1998).

3. Oertel, G. - "Polyurethane Handbook", Hanser Publishers, New York (1993).

4. Nichetti, D.; Cossar, S. \& Grizzuti, N. - Journal of Rheology, 48, p.691 (2004).

5. Nichetti, D.; Cossar, S. \& Grizzuti, N. - Journal of Rheology, 49, p.1361 (2005).

6. Lu, Q.-W.; Hernandez, M. E. \& Macosko, C. W. - Polymer, 44, p.3309 (2003).

7. Woods, G. - “The ICI Polyurethanes Book”, John-Wiley, New York (1987).

8. http://www.basf.com.br/poliuretanos (17/05/2005).

9. Gronqvist, R. \& Hirvonen, M. - International Journal of Industrial Ergonomics, 16, p.191 (1995).
10. Manning, D. P. \& Jones, C. - Applied Ergonomics, 32, p.185 (2001).

11. Li, K. W. \& Chen, C. J. - Applied Ergonomics, 35, p.499 (2004).

12. http://www.hausthene.com.br/elastomeros.htm (11/03/2005).

13. Korodi, T. \& Marcu, N. - Polymer, 24, p.1321 (1983).

14. Korodi, T.; Marcu, N. \& Tirnaveanu, A. - Polymer, 25, p.1211 (1984).

15. Dai, X.; Liu, Z.; Wang, Y.; Yang, G.; Xu, J. \& Han, B. - The Journal of Supercritical Fluids, 33, p.259 (2005).

16. Olin Corporation - Terms and Formulas Used in Urethane Polymer Preparations: Technical Product Information, CT 06856-4500, 2 (1996).

17. David, D. \& Staley, H. B. - "Analytical Chemistry of the Polyurethanes”, Wiley Interscience, New York, 1969.

18. American Society for Testing and Materials - a) "Standard Test Methods for Polyurethane Raw Materials: Determination of Water Content of Polyols ASTM D 4672-87"; b) "Standard Test Methods for Polyurethane Raw Materials: Determination of the Isocyanate Content of Aromatic Isocyanates ASTM D 5155-96"; c) "Standard Test Methods for Flexible Cellular Materials - Slab, Bonded, and Molded Urethane Foams - Density ASTM D 3574 A-95"; d) "Standard Test Methods for Rubber Property - Durometer Hardness ASTM D 2240-97”; e)“Standard Test Methods for Vulcanized Rubber and Termoplastics Elastomers - Tension ASTM D 412-98a"; f) "Standard Test Methods for Tear Strenght of Conventional Vulcanized Rubber and Termoplastics Elastomers ASTM D 624-98"; g) "Standard Test Methods for Rubber Properties in Compression ASTM D 575-96"; h) "Standard Test Methods for Flexible Cellular Materials - Slab, Bonded, and Molded Urethane Foams - Resilience (Ball Rebound) Test ASTM D 3574 H-95"; i) "Standard Test Methods for Rubber Property - Compression Set Under Constant Deflection in Air ASTM D 395 B-98"; j) "Standard Test Methods for Rubber, Raw - Determination of Gel, Swelling Index, and Dilute Solution Viscosity ASTM D 3616 - 95”, West Conshohocken (2000).

19. SENAI - CENTRO TECNOLÓGICO DO CALÇADO. "Método CTC SENAI S-014/ME:2004”, Novo Hamburgo (2004).

20. Deutsches Institut Fur Normung - "Testing of rubber and elastomers - Determination of abrasion resistence DIN 53516 - 87", Alemanha (1987).

21. http://www.hyperlast.com/shock.htm (04/04/2007).

22. Lee, B. S.; Chun, B. C.; Chung, Y. C.; Sul, K. I. \& Cho, J. W. - Macromolecules, 34, p.6431 (2001).

23. Chen, T. K.; Chui, J. Y. \& Shieh, T. S. - Macromolecules, 30, p.5068 (1997).

24. Bajsic, E. G.; Rek, V.; Sendijarevic, A.; Sendirajevic, V. \& Frish, K. C. - Polymer Degradation and Stability, 52, p.223 (1996).

25. Santos, E. M.; Aguiar, M.; Maria, A. F.; Oliveira, C.; Zawadzki, S. F. \& Akcelrud, L. - Polímeros: Ciência e Tecnologia, 10, p.64 (2000).

26. Lefebvre, J.; Bastin, B.; Brás M. L.; Duquesne, S.; Paleja, R. \& Delobel, R. - Polymer Degradation and Stability, 88, p.28 (2004).

27. Gopakumar, S. \& Nair, M. R. G. - European Polymer Journal, 41, p. 2002 (2005)

28. Beck, R. A. \& Truss, R. W. - Polymer, 40, p.307 (1999).

29. Brandrup, J. \& Immergut, E. H. - "Polymer Handbook", $3^{\text {th }}$, John Wiley and Sons, New York (1989).

Enviado: 02/01/07

Reenviado:10/04/07

Aceito: 16/04/07 